This is the penultimate draft of a paper that appeared in Studies in History and Philosophy of Science Part A, vol. 57 (2016): 106-113. The final stages of the research reported here were funded by ERC AG 339382.

\title{
Relativism in Feyerabend's Later Writings
}

Martin Kusch

\section{Introduction}

Forty years ago, Imre Lakatos and Elie Zahar called Paul Feyerabend "our most brilliant cultural relativist" (1975: 367). Not everyone at the time agreed with the expression "most brilliant", but there certainly was widespread agreement that to discuss relativism meant, first and foremost, to engage with the author of Against Method. Today the situation has changed. In the contemporary literature on relativism one finds only brief and perfunctory references to Feyerabend's work. Indeed, one might even say that Feyerabend is "treated as a dead dog" - to echo Marx' famous lament about the absence of Hegel in socialist discourse of the 1860s (Marx 1980: 27).

This paper is an attempt to work out whether Lakatos' assessment is dated and whether we today are justified in ignoring Feyerabend's contributions. In other words, I aim for a re-evaluation of Feyerabend's considerations for and against different versions of relativism. Given limitations of space, my re-evaluation will have to be limited in scope. First, I shall restrict myself to the writings from the late 
seventies to the mid-nineties, especially to Science in a Free Society (1978), Farewell to Reason (1987) and Conquest of Abundance (1999). Needless to say, I leave aside the texts prior to Science in a Free Society not because they are unimportant, but because they demand a separate and detailed investigation. Moreover, and second, I shall say nothing on the thorny topic of incommensurability. This part of Feyerabend's oeuvre has recently been investigated in considerable depth by several scholars, and I have little to add to their results (Hoyningen-Huene 2000, Oberheim 2007, Preston 1997, Sankey 2011).

My paper has six parts. In sections 3 to 6 I shall go over Feyerabend's claims for and against relativism in some detail, sticking closely to the original texts, and offering something of a running commentary. Perhaps this is not the most rhetorically elegant mode of presentation, but it seems best suited to track the changes - book by book - in Feyerabend's thinking. Section 7 attempts an overall summary assessment. I begin, in section 2 with an introduction to what I shall throughout refer to as the "standard model of relativism".

\section{The Standard Model of (Epistemic) Relativism}

The expression "standard model of relativism" is to be taken with a large pinch of salt. It is not meant to refer to an eternal or universally accepted standard. "Standard model of relativism" merely seeks to capture some currently popular characterisations of variants of the position. I have arrived at this model by collecting definitions and characterisations of relativism from both friends and foes

of the view, including Barry Barnes and David Bloor (1982), Paul Boghossian (2006), 
Gilbert Harman (Harman and Thomson 1996), Gideon Rosen (2001), F.F. Schmitt (2007), Bernard Williams (1981), and Michael Williams (2007). Feyerabend's texts were not consulted. My aim was to have an independent and stable standard against which to measure his changes in view. Finally, the suggested model could of course be developed at much greater length than I have space for here. I shall take up this challenge elsewhere. But I hope that even in its current sketchy form the model can be used as a grid or foil for understanding Feyerabend's position. I shall explain this model focusing - as an example - on epistemic relativism.

(1) Dependence: A belief has an epistemic status (as epistemically justified or unjustified) only relative to an epistemic system or practice (=SP). (Cf. Williams 2007: 94).

I write "epistemic system or practice" in order to indicate that Dependence is compatible with both a "generalist" and "particularist" understanding of epistemology. Dependence also allows for a further choice regarding SPs. In saying that a belief has an epistemic status (as justified or unjustified) only relative to an $S P$, the relativist might refer to either the $S P$ of the relevant believer, or to the $S P$ of the attributor or evaluator. (Cf. White 2007, Williams 2007, Boghossian 2006: 72).

(2) Plurality: There are, have been, or could be, more than one such epistemic system or practice. 
Given Plurality, relativism is compatible with the idea that our current $S P$ is without an existing alternative. Moreover, Plurality permits the relativist to be highly selective in choosing those SPs with respect to which relativism applies. He might for example restrict his relativistic thesis to just two SPs. For instance, one can be a relativist about science and religion, considering each an $S P$ in the sense of Dependence.

(3) Exclusiveness: SPs are exclusive of one another. This can take two forms:

(a) Question-Centered Exclusiveness: There are sets of yes/no questions to which SPs give opposite answers.

(b) Practice-Centered Exclusiveness: There are no yes/no questions to which SPs give opposite answers since their concepts and concerns are too different. $S P$ s exclude each other in that the consequences of one $S P$ include such actions or behaviors as are incompatible with the actions and behaviors that are consequences of other SPs. Users or members of one $S P$ are not able to fully understand the actions and behaviors common in other SPs. (Williams 1981, 1985).

Exclusiveness tries to capture the sense in which - under a relativistic conception of their relationship - SPS have to conflict. This idea is in tension with the further assumption, made by some authors, that relativism concerns incommensurable SPS (here such incommensurability involves differences in categories that rule out an identity of propositional content across these SPs). The option of Practice-Centered Exclusiveness covers this eventuality. Two SPs can be compared, and can conflict, 
when they lead to, or require incompatible forms of action and behavior in an at least roughly specifiable area of human affairs. The requirement that the area of human affairs be specifiable safeguards that there is a certain degree of comparability. And the demand that the forms of action and behavior involved are incompatible, makes sure that the condition of conflict is met.

(4) Notional Confrontation: It is not possible for a group $G$ holding an epistemic system or practice $S P_{1}$, to go over to an epistemic system or practice $S P_{2}$ on the basis of a rational comparison between $S P_{1}$ and $S P_{2}$. But $G$ might be converted to $S P_{2}$ without losing its hold on reality. (B. Williams 1981, 1985)

A "notional" confrontation differs from a "real" confrontation; in the case of the latter a rationally motivated 'switching' is possible. A conversion is not an altogether irrational event. Being converted to a cause is not the same as being self-deceived, brainwashed or drugged. There is no assumption that a conversion is a phenomenon of psychological or social pathology. This idea is captured by the phrase "without losing its hold on reality" (Williams 1981: 139).

(5) Symmetry: Epistemic systems and practices must not be ranked. ${ }^{1}$

\footnotetext{
${ }^{1}$ But why couldn't the relativist deny that there is a uniquely best system or practice while at the same time allowing that there are better and worse social practices? (I am grateful to one of my referees for raising this objection.) On the model of relativism suggested here, this position would not amount to a full-blown relativism. While the denial of the unique best system or practice is a relativistic element, the (presumably neutral) ranking of systems or practices into better and worse is not.
} 
Symmetry can take a number of different forms that are worth distinguishing.

(a) Methodological Symmetry: All SPS are on a par vis-à-vis social-scientific investigations.

The best-known version of Methodological Symmetry is perhaps the "Symmetry" or "Equivalence Postulate" of the "Strong Programme" in the "Sociology of Scientific Knowledge": “... all beliefs are on a par with one another with respect to the causes of their credibility" (Barnes and Bloor 1982: 23). I generalize this "postulate" in order to detach it from the requirement that explanations must be causal.

(b) Non-Neutrality: There is no neutral way of evaluating different SPs.

Non-Neutrality is the main consideration usually invoked in defense of Symmetry. It does not preclude the possibility that some SPs agree on the standards by which their overall success should be judged. What Non-Neutrality denies is that such local agreement justifies the hope for a global or universal agreement.

(c) Equality: All SPS are equally correct.

Most characterizations of relativism - by friends and foes alike - take Equality to be the natural consequence of Non-Neutrality and thus the best way to spell out Symmetry. But Equality makes a stronger claim than Non-Neutrality. This becomes 
easy to appreciate once we remember the typical challenge to Equality: what is the point of view from which Equality is asserted? On the face of it, Equality appears to presuppose a neutral point of view from which we can somehow see that all SPs are equally correct. And this very claim jars with Non-Neutrality.

(d) Non-Appraisal: For a reflective person the question of appraisal of (at least some other) SPs does not arise.

Non-Appraisal seems to avoid the problems of Equality, while capturing the important core of Non-Neutrality. It is motivated by the thought of "intellectual distance": the idea that a reflective person holding one SP might come to the conclusion that her own "vocabulary of appraisal" simply does not get a proper grip on the judgments and actions of another SP. It is not that this vocabulary could not possibly be applied at all - it is rather that such application seems forced, artificial and contrived (Williams 1981: 141-2).

Dependence, Plurality, Exclusiveness, Notional Confrontation and Symmetry are (in some version or other) essential features for relativism. The remaining four elements are not essential, though they are its very frequent, almost regular, bedfellows. They are: Contingency, Underdetermination, Groundlessness and Tolerance.

(6) Contingency: Which epistemic system or practice a group G or individual finds itself holding is a question of historical contingency. 
If the history of $G$ had been different - for instance, if $G$ had encountered certain other groups at certain points, or if $G$ had lacked the means to engage in certain types of costly investigations - $G$ 's current $S P$ would be substantially, perhaps even radically, different from what it is now. The contingency might reach deep: even those beliefs that one ordinarily deems 'self-evident' or 'completely certain' can be discovered to be contingent. Becoming aware of the contingency of one's views in this sense can, but need not, undermine the strength of one's conviction (Rosen 2001, cf. also Hacking 1999).

(7) Groundlessness: There can be no non-circular epistemic justification of one's own epistemic system or practice.

Groundlessness is rarely formulated as a distinct ingredient of epistemic relativism. But it is sometimes invoked in arguments meant to establish the truth of relativism. For instance, it is occasionally put forward that epistemic relativism results from the recognition that all SPS are on a par insofar as none of them is able to justify itself without moving in an (illegitimate) circle (cf. Williams 2007: 95). (Needless to say, it might well be possible to advocate a form of relativism that permits such circularity.)

(8) Underdetermination: Epistemic systems and practices are not determined by facts of nature. 
Underdetermination is not to be confused with the thesis that the world has no causal impact on SPS at all. The relativist is not - or need not - be committed to the view that SPS are completely arbitrary. His point is rather that (many) more than one $S P$ is compatible with the given causal impact of the world.

(9) Tolerance: Epistemic systems or practices other than one's own, must be tolerated.

What do we gain from this nine-part characterization in the present context? We gain at least three things. First, we get a better appreciation for the idea that (epistemic) relativism is not one position but a spectrum of positions: the relativist faces a number of choices (e.g. as concerns different Symmetry principles). Second, since the characterization was constructed from the writings of various influential writers on relativism, we get a better grasp too of the variety of views that are currently ascribed to the relativist. And third, using the nine-part characterization as a foil for understanding Feyerabend makes the question of his relativism more tractable. Rather than asking whether Feyerabend is a relativist, we can turn to querying whether we can find textual evidence for the more specific principles. And if we can find such evidence we can then turn to investigating how the different principles are related to one another.

3. Science in a Free Society (1978) 
I now turn to Science in a Free Society. I shall list its main relativistic theses - as these were helpfully compiled by Feyerabend himself - and then explain and comment on some of them, namely theses i., ii., v., vi, and vii. I include the remaining theses for the reader unfamiliar with the book, and interested in the broader context.

“i. Traditions are neither good nor bad, they simply are." (1978: 27)

“ii. A tradition assumes desirable or undesirable properties only when compared with some tradition, i.e. only when viewed by participants who see the world in terms of its values." (ibid.)

“iii. $\quad$ i. and ii. imply a relativism ... defended by Protagoras. ..." (1978: 28)

"iv. Every tradition has special ways of gaining followers. ..." (ibid.)

I shall concentrate on i. and ii. since they are more substantive than iii. and iv. i. and ii. are naturally taken as evidence that Feyerabend accepts at least the following elements of the standard model: Dependence, since he regarded judgements as relative to traditions; Plurality, since there is more than one tradition; Symmetry as Non-Neutrality, since there is no neutral way of evaluating traditions. The wider context of the quoted passages makes abundantly clear that, for Science in a Free Society, traditions are contingent phenomena, groundless and underdetermined by the natural world. Hence Contingency, Groundlessness and Underdetermination are central, too. 
"v. ... individuals or groups participating in the interaction of traditions may adopt a pragmatic philosophy ... The principles of their philosophy often emerge only during the interaction ... This means that judging $a$ historical process one may use an as yet unspecified and unspecifiable practice." (1978: 28)

"vi. There are therefore at least two different ways of collectively deciding an issue which I shall call a guided exchange and an open exchange respectively." (1978: 29)

These two theses are concerned with the interaction between traditions. As Feyerabend explains in the context of vi., "guided exchange" is interaction under the rule of some prior principles, "open exchange" is interaction without such fixed and pre-determined guidance.

As my formulation of Notional Confrontation is meant to bring out, when it comes to the encounter between cultures and traditions, standard relativism tends to put the emphasis on the absence of shared rational procedures. It then goes on to invoke ideas of "conversion" (with overtones of an "irrational" or "a-rational" "jump") as the only way for a given group to switch from one culture or tradition to another. Science in a Free Society avoids this imagery of conversion or jump by focusing on the exchange between traditions rather than on an individual's or a group's whole-sale swapping of one culture or tradition for another.

Moreover, in 1978 Feyerabend insists on the possibility of a particular form of exchange between cultures: an exchange in which the two sides participate with an open-minded and flexible attitude towards their values, commitments and 
principles. The guiding image in Science in a Free Society for the exchange with another culture is thus the transformative dialogue concerning values, commitments and principles. Feyerabend does not explicitly reject Notional Confrontation, but he undermines the presupposition on which it is based: to wit, that the confrontation with another culture is either based on a rational comparison based on fixed principles - "guided exchange" - or that it must take the form of an a-rational or irrational jump or conversion. This idea of "open exchange" is of course closely related to the idea of Tolerance.

Finally, it makes sense, in light of the above, to attribute some version of Exclusiveness to Science in a Free Society. If Exclusiveness did not characterize the relationship between cultures then there would be little cause for exchange and interaction.

We can round off the discussion of Science in a Free Society by attending to theses vii. to $\mathrm{x}$ :

"vii. A free society is a society in which all traditions are given equal rights ..." (1978: 30)

"viii. ... a free society will not be imposed but will emerge only where people solving particular problems in a spirit of collaboration introduce protective structures of the kind alluded to. Citizen initiatives on a small scale, collaboration between nations on a large scale are the developments I have in mind. (1978: 30)

"ix. The debates settling the structure of a free society are open debates not guided debates." (1978: 30) 
"x. A free society insists on the separation of science and society." (1978:

For present purposes we can leave aside viii. to x. But vii. is important. It formulates what Feyerabend later in the book calls "political relativism". He distinguishes it from "philosophical relativism, that is, the thesis that all traditions, theories ... are equally true or equally false ..." (1978: 82-84) Taken in this way vii. is important for identifying Feyerabend's particular Symmetry principle: he rejects an epistemic or semantic Symmetry as Equality, but he accept a political version. He does not claim that all tradition or their beliefs are equally true or equally correct, but he maintains that all traditions should be treated as equal.

To sum up these brief reflections on the position of Science in a Free Society: the relativism of this book is not very far from the standard model. Dependence, Plurality, Exclusiveness, Symmetry as Non-Neutrality, Contingency, Groundlessness, Underdetermination, and Tolerance, are all there. But there are also interesting deviations from, or at least modifications of, the standard model. These are the formulation of a political relativism with Symmetry as Political Equality as its core, a rejection of Symmetry as Equality of truth, and the replacement of Notional Confrontation with the idea of a transformative dialogue. 
The discussion of relativism in Farewell to Reason is much longer and complex than that of Science in an Free Society. Feyerabend puts forward eleven claims or theses that can be brought under four main headings:

"R1 Practical Relativism"; it stresses how much we gain from studying other cultures.

"R2-6 Democratic Relativism"; it insists on equal rights and opportunities for all traditions. It also encompasses the demand that citizens, and not experts, should have the final say in social-political decision-making.

"R7-9 Against Objectivism"; these three theses oppose the idea of a universal truth, and claim that the search for such truth is central to only one tradition.

"R10-11 Epistemic Relativism": this is the key thesis of Ancient Scepticism.

Not all of these theses have the same weight, and some are historical rather than systematic-philosophical claims. The first thesis, $R 1$, formulates "practical relativism" as follows: "Individuals [and] groups ... may profit from studying alien cultures ..." (1987: 21). Farewell to Reason distinguishes between different depths regarding the implementation of practical relativism, ultimately favouring a form according to which "... even our most basic assumptions ... can be changed ..." in such cross-cultural interactions (1987: 22). Practical relativism is opposed to socalled "objectivism"; the latter holds that one's own culture is superior to all others, and that one therefore has little to learn from them. Farewell to Reason does not give a general argument for practical relativism. It merely attacks one specific form 
of objectivism, namely "... the idea that science overrules all other forms of life ..." (1987: 36).

I shall be brief in my comments on $R 1$. Practical relativism is not a familiar form of relativism. Nevertheless, practical relativism may be read as expanding the theme (from Science in a Free Society) of transformative dialogue and the related rejection of Notional Confrontation. Be this as it may, Feyerabend's case for practical relativism, for all its brevity, seems to me to be compelling. We surely should not rule out from the start that there are things we can learn from other cultures.

Feyerabend's 1987 account of "democratic relativism" is more important for present purposes:

"R2-R3 Democratic societies should give ... all traditions equal opportunities ... and equal rights." (1987: 39-40)

"R4 Laws, religious beliefs and customs ... are valid in their [respective restricted] domains." (1987: 42)

"R5 Man is the measure of all things ..." (1987: 44) ... "Important matters should ... be referred to the (...) people concerned ..." (1987: 47)

"R6 Citizens ... have the last word in deciding what is true or false, useful or useless for their society. ..." (1987: 59)

In the context of $R 5$ and $R 6$ Feyerabend rejects Plato's rendering of Protagoras' "homo-mensura" thesis. For Farewell to Reason Protagoras is not saying that what seems to be true to an individual is true. Rather "man is the measure" means that 
"important matters should ... be referred to the (...) people concerned ..." (1987: 47) Moreover, Feyerabend suggests that Protagoras' infallibilism provides support for Protagoras' anti-expertism: since there is no meaningful distinction between true/objective and false/subjective realities, there is no special ground on which experts can stand.

My first comment on R2-R6 is that, pace Farewell to Reason, Democratic Relativism is not an obvious consequence of Practical Relativism: that we are able to learn from other traditions does not mean that they all deserve equal rights maybe some traditions are more useful to us than others. My second comment is to note that $R 2-R 3$ expresses Symmetry as Political Equality, a view already central to Science in a Free Society. Third, Feyerabend's intriguing re-interpretation of the Protagoras of Plato's Theaetetus seems worthy of a more detailed analysis in a different context; it makes contact with some of the best recent literature on the topic by presenting Protagoras as an infallibilist rather than a relativist (Fine 1996, cf. Lee 2005). Moreover, Feyerabend interestingly situates Plato's dialogue in contemporaneous Athenian debates over experts and their role in democracy. Of course, Farewell to Reason does not endorse all facets of Protagoras' position. Fourth, the Democratic Relativism of the 1987 book may be more radical than what was offered in Science in a Free Society nine years earlier. In 1987 truth itself is said to be under democratic control: "Citizens ... have the last word in deciding what is true or false ..." Finally, Democratic Relativism clearly involves Dependence, Plurality, and a version of Symmetry as Equality: all cultures are on a par in that their members are entitled to decide what is true or false, useful or useless for them. 
The sketches of Practical and Democratic Relativism are followed by some reflections against objectivism and its assumption of universal truth:

"R7 The world, as described by our scientists and anthropologists, consists of (social and physical) regions with specific laws and conceptions of reality. ... The attempt to enforce a universal truth ... has led to disaster in the social domain and to empty formalism ... in the natural sciences." (1987: 61)

"R8 The idea of an objective truth or an objective reality ... is part of a special tradition which, judged by its own members, contains successes as well as failures ..." (ibid.)

"R9 The idea of a situation-independent objective truth has limited validity. ... it rules in some domains (traditions), but not in others." (ibid.)

Only $R 7$ provides something of a case against objectivism; it argues from the allegedly negative consequences of adopting it: "The attempt to enforce a universal truth ... has led to disaster in the social domain and to empty formalism ... in the natural sciences." (ibid.) Let us grant that objectivism has a mixed record and is but one tradition. That still does not tell us enough to know what exactly makes one an objectivist. Is it enough to believe in universal truth? Is it enough to believe in a mind-independent reality? Or is it enough simply to believe in universal epistemic standards? Since these issues are left open, it is impossible to determine Feyerabend's alternative. It might be metaphysical pluralism, that is, the view that different domains obey different laws; it might be ontological relativism, that is, 
metaphysical pluralism plus the claim that the different domains are made by us; or it might be epistemic relativism, that is the view that there are different and incompatible standards of epistemic justification. Ontological relativism is alluded to where Feyerabend stresses the ineradicable "human element" in our knowledge. For him Greek gods and theoretical entities are ontologically on one par: "Both are objective in intention and both arose in a culture-dependent way ..." (1987: 88).

Epistemic relativism is the topic of theses $\mathrm{R} 10$ and $\mathrm{R} 11$ :

"R10 For every statement (theory, point of view) that is believed to be true with good reasons there may exist arguments that either its opposite, or a weaker alternative is true." (1987: 74)

"R11 ... there exist arguments showing a conflicting alternative to be at least as good, or even better." (1987: 76)

The main consideration offered in defence of $R 11$ is that objectivists have not conclusively disproven it (1987: 77). Feyerabend himself notes that $R 11$ is a key idea of Ancient scepticism. And, interestingly enough, his own general view of arguments in defence of relativism too is sceptical (1987: 78): he claims that all of the arguments for R1-R11 are merely ad hominem arguments against the objectivist. (Recall that interpreting arguments for scepticism as ad hominem arguments against the dogmatists is the classical sceptical move for avoiding self-refutation.) True, Farewell to Reason does cite the theory of evolution and the "discoveries of historians and anthropologists" as providing some kind of case for relativism. But 
this pronouncement is quickly followed by yet another reminder that relativism cannot be defended - at least not in "objective" ways (1987: 78).

Some of Feyerabend's reflections on $R 10$ and $R 11$ are less than fully convincing. For instance, it does not seem plausible to say that Feyerabend here uses a sceptical idea in order to defend a relativistic thesis - what he calls "epistemic relativism" simply is what the Ancients called "scepticism". In other words, R10 and R11 motivate a form of sceptical غ̇лoxń towards scientific theories. Or put still in another way, the Symmetry as Equality involved here is not that all cultures are equally correct but that all views have - to use modern jargon - important and, ultimately not-to-be-ignored, undefeated defeaters.

My assessment of Farewell to Reason can be summed up as follows. The book introduces, and seeks to defend, a variety of different forms of relativism. "Practical relativism" is very far from positions ordinarily classified as relativistic. "Epistemic relativism" is really Ancient scepticism. "Democratic relativism" is first and foremost a form of anti-expertism. In Feyerabend's version it is relativistic since it seems linked to other elements of the standard model, such as Dependence, Plurality, Symmetry as Equality of Truth, and Symmetry as Political Equality. Finally, the critique of "objectivism" suffers from the fact that too many ills are packed into this position. Accordingly Feyerabend's alternative remains unclear.

Comparing, however briefly, Science in a Free Society with Farewell to Reason, the former obviously is much closer to the "standard model" than the latter. After all, Farewell to Reason introduces a range of novel forms of relativism usually without bothering much about connecting tissue between the old and the new. Clearly, the central thread of both books is political or democratic relativism. 
And indeed, the attention for parallels and interactions between political, ontological and epistemic forms of relativism is perhaps the two books lasting and still largely unexplored legacy.

\section{Writings after 1987 I: The Criticism of Relativism}

I next turn to Feyerabend's writings after 1987, giving pride of place to the material in Conquest of Abundance (1999). I begin with the criticism of relativism that runs through pretty much all of the later writings.

A useful first task is to compile from Feyerabend's writings a characterization of the form of relativism he now finds objectionable. The result has the following ingredients:

$R(i) \quad$ The aim is a "theory of knowledge" (1993: 269), providing a "definition or a theory of truth and/or reality" (1991a: 513).

$R($ ii) There is no "single human nature" (1995: 152).

R(iii) “... Cultural peculiarities are sacrosanct." (1995: 152)

$R$ (iv) Cultures are "equally truthful messengers of reality" (1999: 122), and are "equally successful” (1999: 215).

$R(v) \quad$ Claims are "valid only 'within a system", consisting of "unambiguous" and "well-defined rules" (1991b: 151; 1993: 138, 188, 198).

$R(v i) \quad$ A culture is confirmed by everything within it. (1999: 249). Every question is either "answer[ed] or ... regard[ed] ... as nonsensical." (1999: 215) 
R(vii) Cultures are "closed" (1999: 31); "cannot learn" from each other (1991b: 152); and "do not get entangled with each other" (1999: 123). $R$ (viii) It takes a "revolution" for one culture to replace another (1991b: 19).

It is easy to match most of these to elements of the standard model: $R(i i)$ to Contingency and Groundlessness, R(iii) to Tolerance, $R($ iv) to Symmetry as Equality, $R(v)$ to Dependence, $R(v i)$ to Underdetermination, $R(v i i)$ and $R($ viii) to Notional Confrontation and Exclusiveness. But as we shall see momentarily, Feyerabend's characterization involves radical or extreme versions of most of these elements.

Who then does Feyerabend take to be advocates of this position? Oddly enough, this is an issue on which he remains largely silent. Sometimes Feyerabend sounds as if his later criticism of relativism was a criticism of his former self. At other times he en passant links allegedly unacceptable forms of relativism to Richard Rorty (1979) or the Sociology of Scientific Knowledge, and especially D. Bloor (1976). Other well-known positions in the vicinity of Feyerabend's target position - say, Peter Winch (1958) or the views of self-proclaimed "cultural relativists" like Melville J. Herskovits (1973) - are never mentioned. In what follows I shall review to what extent these authors are guilty of Feyerabend's charges. ${ }^{2}$

Turning then to Feyerabend's criticism of relativism, he frequently presents this criticism under the title "potentially every culture is all cultures" (e.g. 1999: 33). But I shall take his points one by one. To repeat, $R(i)$ is the idea that relativism aims for a "theory of knowledge" that provides a "definition or a theory of truth and/or

\footnotetext{
${ }^{2}$ One of my referees suggests that Feyerabend is targeting "popular rather than theoretical forms of relativism". Maybe so. But since it is hard to tell what such popular relativism amounts to, I shall set it aside here.
} 
reality", or that "explains the relation between humans and the world and provides a philosophical grounding". Against this position Feyerabend simply insists without much argument - that “... there can at most be a (rather incomplete) history of the ways in which knowledge has changed in the past ..." (1993: 269).

It is not difficult to imagine types of arguments that would support Feyerabend here. These are familiar objections to foundationalist philosophical theories about the relationship between humans and the world. But who are the relativists who have presented such theories? Feyerabend himself never did. And neither do Bloor, Herskovits, Rorty or Winch, even though Bloor is accused of doing so at one point (1991b: 155). Needless to say, there is some theory in Bloor: a methodology for social studies of science, a rough sketch of relativism, and a Wittgensteinian theory of language-use called "meaning finitism". It is unclear whether this is enough to convict Bloor of the charge. Feyerabend himself offers as least as much theoretical argument in defence of his own positions.

$R($ ii) is the claim that there is no "single human nature". Feyerabend replies that "... special cultural features are changeable manifestations of a single human nature." (1995: 152). This again is just pitting claim against claim. Note also that the denial of human nature is not an essential part of the standard model. At best this denial is one radical (and, as such implausible) way of spelling out Contingency or Ungroundedness. Indeed, relativists as well as their critics have noted before that accepting relativism does not force one to reject human nature (e.g. in the form of universals). Here for example is Ernest Gellner (1982: 183): "Relativism is perfectly compatible with the existence of any number of, so to speak, de facto or contingent 
human 'universals' ..." Bloor routinely agrees (e.g. 2007: 267), and Herskovits makes similar pronouncements (1973: 15-16).

Feyerabend also objects to $R($ iii): "Cultural peculiarities are sacrosanct" (1995: 152). The counterclaim is that “... cultural peculiarities are not sacrosanct. There is no such thing as a 'culturally authentic' suppression ... There is only suppression." This does not mean that Feyerabend wishes to steamroll other cultures into accepting our criteria and our remedies: “... we must pay attention to the wishes, the opinions, the habits, the suggestions of the people to be interfered with ..." (1995: 152).

On first sight, $R$ (iii) might look like the position that Feyerabend held in Science in a Free Society or Farewell to Reason. Did he not insist there that cultures are equal and does that not suggest that other cultures are sacrosanct? While it is true that Feyerabend did indeed think of cultures as equal, he was not thereby committed to treating them as sacrosanct. Recall for instance the importance that Science in a Free Society gives to the phenomenon of transformative dialogue between cultures. Note also, and more generally, that political relativism or Tolerance are not directly implied by epistemic or moral relativism. $R($ iii) is not a good fit with the writings of Herskovits either, albeit that the latter writes that "... cultural relativism is a philosophy that recognizes the values set up by every society to guide its own life ..." (1973: 31) Herskovits is not committed to treating these values as "sacrosanct".

Feyerabend rejects $R$ (iv) - that cultures are "equally truthful messengers of reality" (1999: 122), or "equally successful" (1999: 215) - on the grounds that "not all approaches to 'reality' are successful" and that the success of cultures is "a 
matter of empirical record, not of philosophical definitions ..." (ibid.) Or as he puts it in another context: "Different forms of life and knowledge are possible because reality permits and even encourages them and not because 'truth' and 'knowledge' are relative notions ..." (1991a: 516)

What Feyerabend here discounts is Symmetry as Equality of truth and success; he did so already in Science in a Free Society and Farewell to Reason. Of course, Equality is not the only option under Symmetry. Perhaps most importantly, the early Feyerabend did stress (e.g. in 1981: 343) that different cultures have very different criteria of success. By the nineties he instead seems to assume that such criteria are shared, or at least that our criteria can be applied to other cultures in a fair manner. Surely at this point one would expect an explanation as to why the earlier position was given up.

I shall discuss $R(v)$ to $R($ viii) as one group since these four theses are closely intertwined. Feyerabend's main objection is that "traditions not only have no welldefined boundaries, but contain ambiguities and methods of change which enable their members to think and act as if no boundaries existed ..." (1999: 142) His model here are languages: "speaking a language ... means both following rules and changing them" (1999: 125); and the rules are "ambiguous" in that future use is largely unknown" (1999: 77). Moreover, "... 'real' cultures" change when they face problems; they are built for interaction with other cultures" (1999: 123, 216). And finally, relativism obscures phenomena of cultural change, insofar as for the relativist "we are forever stuck in a system until a miracle gives us another system, and then we are stuck in that one." (1991b: 19) 
It is easy to agree with Feyerabend, that the form of relativism he attacks here is unattractive. But we also need to ask whether relativism in general is committed to $R(v)$ to $R($ viii). And it seems to me that relativism is not so committed. First, the relativist need not be a generalist and emphasise "systems" of principles. The relativist might instead adopt a particularist stance and emphasise practices (as Bloor, Rorty or Winch all do). Second, the relativist need not claim that principles or precedents predetermine outcomes. She might stress merely that all determinants are local and contingent (as the Sociology of Knowledge does). Third, relativism need not think of cultures as unified and homogeneous (cf. David Wong's idea of "cultures as conversations" (2009)). Fourth, nor is relativism committed to thinking of cultures as "closed". Herskovits makes this pretty clear when he writes: "No culture ... is a closed system ..." (1973: 15). And the relativistic Sociology of Knowledge usually studies controversies, that is, cultures in conflict, trying to change each other. Fifth, relativism need not maintain that cultural systems are "self-vindicating" and that their change or replacement is therefore beyond explanation. Self-proclaimed relativists (in the Sociology of Knowledge and in anthropology) aim to offer precisely such explanations. Sixth, a brief comment seems in order on the mantra of Feyerabend's criticism: "Potentially every culture is all cultures". This is true insofar as most cultures can learn from many others. But such learning might change the learning culture beyond recognition. And then the slogan should be: every culture can be replaced. Now, why should the relativist deny this? Seventh, and finally, to the best of my knowledge, Feyerabend never held any of $R(v)$ to $R$ (viii). 
Let me sum up my assessment of Feyerabend's criticism of relativism. All elements of the standard model of relativism are present in the position under attack. Alas, Feyerabend reduces relativism to holding extreme versions of the elements (e.g. Contingency as denial of human nature). In so doing, he sets the bar too low: it is easy to show that this extreme (straw-man) version of relativism is problematic. And it remains unclear which authors Feyerabend took himself to be criticising. Neither he nor Bloor, Herskowits, Rorty or Winch are guilty of the charges. It probably would have made for a more compelling exercise in case the Feyerabend of Conquest of Abundance had focused critically on his own previous selves, especially the Feyerabend of Science in a Free Society and Farewell to Reason.

\section{Writings after 1987 II: Ontological Relativism}

Late in his life, Feyerabend reported having "started using the term 'relativism' again, but in a new sense" (1999: 269). What did this involve?

To begin with, it involved the claim that science as well as religion "project" entities. They both assume that these entities "exist independently" of practices (1999: 133). Both types of projection, Feyerabend claims, are frequently successful insofar as they sometimes lead to previously unknown effects (1999: 139). Moreover, scientists using "combined causal-semantic action" (1999: 145), “manufacture ... [e.g.] ... particles out of a material that did not contain these elements but could be shaped into them" (1999: 144). This material occasionally offers "resistance", at least more resistance than the Sociology of Knowledge allows 
for. Nevertheless, this material is "pliable": "Moulding it one way (...), we get elementary particles; proceeding in another, we get ... Gods." (1999: 145) Feyerabend also believes that "ultimate Reality, or Being ... is ineffable. But we have access to the ways in which Ultimate Reality reacts to our approach." (1999: 214). And finally, experimental interference in nature teaches "how Nature responds to the interference", rather than how "She Is In and For Herself" (1999: 239).

Three considerations are invoked to support the last-mentioned thought. First, different interferences lead to incompatible results (1999: 238). Imagine each individual of a group separately asking me questions in order to find out what kind of person I am. Does each individual thereby find out what I am like in and for myself, or does she learn what images of myself I seek to convey to different individuals of the group? Feyerabend thinks that the less the different answers to different questions cohere, the more likely it is that the latter option (different images for different people) is the correct one. Mutatis mutandis for Nature and our experimental and cultural interferences. A second reason for agnosticism concerning Nature is that "... non-scientific cultures [too] provided acceptable lives for their members ..." (1999: 239). A third reason is quantum mechanics. It has taught us that "properties once regarded as objective depend on the way in which the world is being approached ..." (1999: 240)

It is difficult to offer substantive and fair comments on ideas that are so sketchy and so little worked out. But here goes. As far as "successful projections" are concerned, Feyerabend wants the projections of electrons and of Gods to be both "successful" - and without making "success" relative to cultures or traditions. It is hard to see how this is supposed to work. Of course, both the positing of Gods 
and the positing of electrons has (had) some "unforeseen effects". Nevertheless, should we not expect that different cultures have rather different standards for what count as "effects" or "success"?

Feyerabend's idea that our knowledge of nature is limited to how nature responds to our interferences is not a radically new theme. Call it the "humility theme". It is central for instance in the Kantian tradition (e.g. Langton 1998), in constructive empiricism (van Fraassen 1980) or in an influential reading of Thomas Kuhn (Hoyningen-Huene 1993). Feyerabend himself admits as much: "our views (i.e. my published views and Kuhn's as yet unpublished recent philosophy) by now seem to be almost identical" (1993: 219)

The talk of "manufacturing particles" or "sculpting reality" resonates also with another body of literature: the Sociology of Scientific Knowledge and the work of Bruno Latour and Steven Woolgar (1986). Feyerabend writes: "... 'scientists ... are sculptors of reality.' That sounds like [the Sociology of Scientific Knowledge] ... except that the sculptors are restricted by the ... material" (1999: 269). I have already pointed out that - as far as the work of Bloor is concerned, this is a false contrast. Bloor does not deny the world independent causal agency, he insists on it (Bloor 1999). The parallel with Latour's and Woolgar's "construction of scientific facts" works better. Saddling Feyerabend with this position might not be doing him a favor however (Kusch 2012).

Feyerabend writes that both electrons and Gods exist, and he justifies his position with reference to Ultimate Reality's willingness to be successfully molded in both of these ways. In light of the work of van Fraassen and others this quick step from success to existence should have felt problematic. At least one would expect 
an awareness of the hefty metaphysical and epistemological assumptions needed to underwrite it. Furthermore, Feyerabend infers the impossibility of knowing Ultimate Reality from the existence of incompatible experimental results. Again this is based upon an unacknowledged metaphysical assumption, to wit, that Ultimate Reality does not have incompatible sides or aspects. And finally, in places it seems that Feyerabend wishes to advance an argument from methodological to metaphysical pluralism, from a plurality of methods (successful in prediction) to a plurality of worlds (of some kind or other). After all, this motivates his talk of "ontological relativism". Again, we are asked to adopt heavy-weight metaphysical assumptions, and the Kantian humility seems to have been thrown into the wind.

\section{Conclusion}

Let me sum up. In this paper I have sought to reconstruct, and distinguish between, Feyerabend's different forms of relativism in his later writings. The central results were the following.

Science in a Free Society (1978) remains close to a standard model of relativism, while, at the same time, developing an original but under-argued form of political relativism, and rejecting "conversion" models of cultural exchange.

Farewell to Reason moves away from standard conceptions of relativism, and develops a range of different new forms. The links to other "isms" (skepticism, infallibilism) are intriguing. But they are vaguely suggested rather than fully explicated. 
In the last six years of his life, Feyerabend often criticizes a peculiar radical form of relativism that arguably no-one has ever proposed or defended. In the same context, Feyerabend sketches an "ontological" form of relativism. It combines "Kantian humility", metaphysical pluralism and constructivism.

While many of Feyerabend's arguments and ideas feel dated and weak, some still seem timely and well worth investigating further. Here I am thinking especially of ontological and democratic forms of relativism.

To expand on this "verdict", the first thing to say is that from a historical perspective, all of Feyerabend's writings on relativism obviously deserve further study. It would for instance be interesting to learn more about various influences upon his relativistic thought, or how his views have influenced later writers. From a systematic perspective, of lesser interest seem to be his views on epistemic relativism, or his criticisms of objectivism and relativism. At best they teach us "via negativa" that epistemic relativism and skepticism are best kept apart; that "objectivism" covers too many ills to be a useful category; or that relativism need not be the radical view Feyerabend rejects. Of greater significance from a systematic perspective, are potentially - for all their brevity - his views on ontological and political relativism.

As far as ontological relativism is concerned, Feyerabend's views might perhaps be usefully related to, or inserted into, contemporary debates over epistemological and metaphysical forms of "scientific pluralism" (Kellert, Longino, Waters 2006; Dupré 1995; Chang 2012). After all the relationship between epistemology and metaphysics, or relativism and pluralism is a constant and central 
theme in these debates. The relevant literature contains only occasional, and usually perfunctory, references to Feyerabend's views.

The case for keeping Feyerabend's ideas alive is still easier to make for the case of "democratic relativism". Contemporary work in Science Studies is full of criticisms of so-called "deficit models" of the public vis-à-vis scientific expertise (e.g. Jasanoff 2003, Wynne 1996). And some philosophers of science are busy trying to bring their field into a close interaction with political philosophy (Douglas 2009, Kitcher 2011, Longino 2001). Feyerabend's project is too close to these recent developments to be ignored. ${ }^{3}$

\footnotetext{
${ }^{3}$ For critical and constructive comments I am grateful to the participants of the Berlin Conference, especially to Matthew Brown, Matteo Collodel, Paul HoyningenHuene, and lan Kidd. I have also profited from the suggestions of two anonymous referees.
} 
Literature

Barnes, B. and D. Bloor (1982), “Relativism, Rationalism and the Sociology of Knowledge", in M. Hollis and S. Lukes (eds.), Rationality and Relativism, Oxford: Blackwell, 21-47.

Bloor, D. (1976), Knowledge and Social Imagery, London: Routledge.

Bloor, D. (1999), "Anti-Latour", Studies in History and Philosophy of Science 30: 81112.

Bloor, D. (2007), “Epistemic Grace”, Common Knowledge 12: 250-80.

Boghossian, P. (2006), Fear of Knowledge: Against Relativism and Constructivism, Oxford: Clarendon Press.

Chang, H. (2012), Is Water H2O? Evidence, Realism and Pluralism, Berlin, New York: Springer.

Douglas, H. D. (2009), Science, Policy, and the Value-Free Ideal, Pittsburgh: University of Pittsburgh Press.

Dupre, J. (1995), The Disorder of Things: Metaphysical Foundations of the Disunity of Science, Cambridge, Mass. Harvard University Press. 
Feyerabend, P. (1978), Science in a Free Society, London: New Left Books.

Feyerabend, P. (1981), "Rückblick", in H. P. Duerr (ed.), Versuchungen: Aufsätze zur Philosophie Paul Feyerabends, 2. Band, Frankfurt am Main: Suhrkamp, 320372.

Feyerabend, P. (1987), Farewell to Reason, London: Verso.

Feyerabend, P. (1991a), "Concluding Unphilosophical Conversation", in G. Munevar (ed.), Beyond Reason: Essays on the Philosophy of Paul Feyerabend, Dordrecht: Kluwer, 487-527.

Feyerabend, P. (1991b), Three Dialogues on Knowledge, Oxford: Basil Blackwell.

Feyerabend, P. (1993), Against Method, 3rd ed. London: Verso

Feyerabend, P. (1995), Killing Time: The Autobiography of Paul Feyerabend, Chicago: University of Chicago Press.

Feyerabend, P. (1999), Conquest of Abundance, Chicago: University of Chicago Press. 
Fine, G. (1996), "Protagorean Relativisms", in J. Cleary and W. Wians (eds.), Proceedings of the Boston Area Colloquium in Ancient Philosophy, 19, Lanham, MD: University Press of America, 211-243.

Gellner, E. (1982), "Relativism and Universals”, in M. Hollis and S. Lukes (eds.), Rationality and Relativism, Oxford: Blackwell, 181-200.

Hacking, I. (1999), The Social Construction of What?, Harvard, Mass.: Harvard Universits Press.

Harman, G. and J. Jarvis Thomson (1996), Moral Relativism and Moral Objectivity, Oxford: Blackwell.

Herskovits, M. J. (1973), Cultural Relativism: Perspectives in Cultural Pluralism, New York: Vintage Books.

Hoyningen-Huene, P. (1993), Reconstructing Scientific Revolutions: Thomas S. Kuhn's Philosophy of Science, Chicago: University of Chicago Press.

Hoyningen-Huene P. (2000), "Paul Feyerabend and Thomas Kuhn", in J. Preston, G. Munevar, D. Lamb (eds.), The Worst Enemy of Science? Essays in Memory of Paul Feyerabend, New York: Oxford University Press, 102-114. 
Jasanoff, S. (2003), “Technologies of Humility: Citizen Participation in Governing Science", Minerva 41: 223-44.

Kellert, S. H., H. E. Longino, C. K. Waters (eds.) (2006), Scientific Pluralism, Minneapolis: University of Minnesota Press.

Kitcher, P. (2011), Science in a Democratic Society, Armherst, N.J.: Prometheus Books.

Kusch, M. (2012), "Sociology of Science: Bloor, Collins, Latour", in J. R. Brown (ed.) Philosophy of Science: The Key Thinkers, London: Continuum Press, 168-187.

Lakatos, I. and E. Zahar (1975), “Why Did Copernicus' Research Program Supersede Ptolemy's", R. S. Westman (ed.), The Copernican Achievement, Berkeley, Los Angeles, London: University of California Press, 354-383.

Langton, R. (1998), Kantian Humility: Our Ignorance of Things in Themselves, Oxford: Clarendon Press.

Latour, B. and S. Woolgar (1986), Laboratory Life: The Construction of Scientific Facts, $2^{\text {nd }}$ ed., Princeton, N.J.: Princeton University Press.

Lee, M.-K. (2005), Epistemology After Protagoras: Responses to Relativism in Plato, Aristotle, and Democritus, Oxford: Oxford University Press. 
Longino, H. E. (2001), The Fate of Knowledge, Princeton, N.J.: Princeton University Press.

Marx, K. (1980), Das Kapital: Kritik der politischen Ökonomie, Erster Band, Berlin:

Dietz Verlag.

Oberheim, E. (2007), Feyerabend's Philosophy, Berlin: de Gruyter.

Preston, J. (1997), Feyerabend: Philosophy, Science and Society, Cambridge, Polity Press.

Rorty, R. (1979), Philosophy and the Mirror of Nature, Princeton: Princeton University Press.

Rosen, G. (2001), “Nominalism, Naturalism, Epistemic Relativism”, Philosophical Perspectives 15: 60-91.

Sankey, H. (2011), "Incommensurability and Theory Change", in S. D. Hales (ed.), A Companion to Relativism, Wiley-Blackell: Chichester, 456-474.

Schmitt, F. F. (2007), "Introduction: Epistemic Relativism”, Episteme 4: 1-9.

van Fraassen, B. (1980), The Scientific Image, Oxford: Blackwell. 
White, R. (2007), “Epistemic Subjectivism”, Episteme 4: 115-129.

Williams, B. (1981), "The Truth in Relativism", in B. Williams, Moral Luck, Cambridge: Cambridge University Press, 132-143.

Williams, B. (1985), Ethics and the Limits of Philosophy, London: Fontana.

Williams, M. (2007), "Why (Wittgensteinian) Contextualism is not Relativism", Episteme 4: 93-114.

Winch, P. (1958), The Idea of a Social Science and Its Relation to Philosophy, London: Routledge and Kegan Paul.

Wong, D. (2009), "Cultural Pluralism and Moral Identity", in D. Narvaez and D. Lapsley (eds.), Personality, Identity, and Character: Explorations in Moral Psychology, Cambridge: Cambridge University Press, 79-105.

Wynne, B. (1996), "May the Sheep Safely Graze? A Reflexive View of the Expert-Lay Knowledge Divide", in S. Lash, B. Szerszynski, B. Wynne (eds.), Risk, Environment \& Modernity, London: Sage, 44-83. 